\title{
Investigation on the pollen morphology of traditional cultivars of Prunus species in Sicily
}

\author{
Anna Geraci* , Vincenza Polizzano, Pasquale Marino, Rosario Schicchi \\ Department of Environmental Biology and Biodiversity, University of Palermo, Via Archirafi, 38-90123, Italy
}

\section{Abstract}

In this study pollen grains of 13 cultivars and 3 rootstocks belonging to 5 species (P. armeniaca, $P$. domestica, $P$. dulcis, $P$. persica, P. avium) of the genus Prunus collected from North-East Sicily were examined for the micromorphological characterization through the scanning electron microscopy (SEM). The length of polar axis $(P)$ and the equatorial diameter $(E)$ of grain, $P / E$ ratio, the length of colpi $(C)$, diameter of perforations $(D P)$ and the number of perforations in $25 \mu \mathrm{m}^{2}(P N)$, the width of muri (WM), the distance between muri $(D M)$ and their number in $25 \mu \mathrm{m}^{2}(M N)$, the width of grooves $(W G)$ were measured and their variation was compared among studied taxa. Moreover multivariate statistical analysis was carried out to distinguish morphometric information from measured parameters. All pollen grains are trizonocolpate, isopolar, medium-large sized and their shape varies from prolate to perprolate. Regarding outline pollen grains are subtriangular in polar view and elliptic in equatorial view. Exine sculpturing is striate with perforations on grain surface. The arrangement of ridges appears roughly parallel but too sloped (sometimes curved) compared to polar axis, or branched and oriented in different directions, or perfectly parallel or more irregular with bifurcated ridges often sinuous. The analyses showed a great variability (particularly in P. domestica cultivars) related in some cases to the diversity in the morphological features of the leaves and the fruits of the investigated entities.

Keywords: pollen morphology, SEM, Sicilian Prunus, species, cultivars

\section{Introduction}

The cultivation of fruit trees and shrubs in the traditional agrosystems of Sicily played a significant role until the years after World War II. Its products were a primary source of nutrition for rural people but also a consistent integration of their income. It was a non-specialized fruit-growing based on mixed systems in which the richness of species and cultivars was primarily aimed at providing fresh and durable fruits for their family consumption.

Since the eighth century BC, Sicily has been subjected to various dominations (Phoenician, Greek, Roman, Arab, Norman) who have contributed to the introduction of different tree species and fruit trees. The wide range of varieties selected over time by the rural communities, closely linked to the economy of the past and the local agricultural practices, has been preserved until half of the twentieth century in the context of traditional agrosystems [1].

* Corresponding author. Email: anna.geraci@unipa.it

This is an Open Access digital version of the article distributed under the terms of the Creative Commons Attribution 3.0 License (creativecommons.org/licenses/by/3.0/), which permits redistribution, commercial and non-commercial, provided that the article is properly cited.
Prunus belongs to the Rosaceae family, subfamily Prunoideae. This genus includes several both wild and cultivated species, mainly deciduous shrubs and trees, distributed in tropical, temperate and sometimes in semiarid regions of the northern hemisphere. It represents an important economical resource because many species produce edible fruits (e.g. plums, peaches, apricots, cherries and almonds), oil, wood and some species are employed as ornamental plants [2].

Prunus is one of the most problematic genera in the family of Rosaceae and its taxonomy is very complicated because of the polymorphism and the wide ecological tolerance of the species, as well as the presence of an enormous number of cultivars [3].

For the identification of plant material, morphological characteristics such as plant vigour and leaf, flower, and fruit parameters could be utilized [4]. In addition to these features, differences in the size and the surface ultrastructure of pollen grain are a useful tool for distinguishing species and cultivars of fruit trees. Using pollen morphology in identification has become more important since the advent of the scanning electronic microscope (SEM) [5-13].

Taxonomists and botanists have recognized the importance of pollen morphology in clarifying the classification of many plants: in particular Hebda et al. [10] showed that exine sculpturing, aperture and aperture zone structure, grain shape and grain size are all useful features to distinguish genera and even species of rosaceous pollen; Fogle [5,6] demonstrated species-specific variation in pollen size and in exine sculpturing among the fruit-crop of the genera Malus 
Mill., Prunus L. (peaches and cherries), and Pyrus L. [14]; Moore et al. [15] have emphasized a very large differentiation of pollen morphology of the taxa of Rosaceae family, even among the populations within the same species. They thought the pollen size to be the least reliable feature and they related it to the comparatively frequent occurrence of hybrid and polyploid species in this family. In the subgenera Sorbus, Chamaespilus and Torminaria belonging to the genus Sorbus, pollen morphology corresponds with their systematic classification [16], while in the genus Rosa, a recent study showed that the exine sculpture can be helpful in distinguishing groups of species although only slightly corroborates division of the genus in subgenera and sections [17].

The purpose of this study is to increase knowledge of the aspects related to the variability of the genus Prunus fruit trees in order to facilitate the emergence of initiative aimed at the characterization and preservation of the germoplasm. For this reason SEM analysis was conducted to characterize the pollen morphology of some Sicilian Prunus cultivars and to evaluate the utility of pollen features in order to develop an additional alternative plant material identification tool.

\section{Material and methods}

In this study the pollen grains coming from 13 cultivars and 3 rootstocks (plants obtained from seeds) belonging to four species of the genus Prunus; in particular P. armeniaca L. (apricot), P. persica (L.) Batsch (peach), P. domestica L. (plum), P. dulcis (Miller) D. A. Webb (almond) were examined (Tab. 1).

The plant samples were collected from fruit-trees grown in orchards or in abandoned fields, both situated in different localities of Madonie Mts. in North-Eastern side of Sicily. The flower buds of cultivars belonging of Prunus species were taken at the balloon stage (just before the opening of the anthers) in order to collect pollen; sepals and petals of the buds were removed, and anthers were isolated, put into petri dishes and kept at room temperature for $24 \mathrm{~h}$. Afterwards, the pollen was sprinkled on the surface. The pollen was further dried at room temperature for 6-8 h and put into vials with silica gel until require for SEM evaluation. Dry pollen grains were sifted onto transparent double-sided tape on the disc surface of polished aluminum stabs. The sample on each stub was sputter-coated with a gold layer ca. 200 A thickness in a vacuum evaporator under certain pressure.

After that, for SEM evaluation, the pollen grains were observed and photographed at 446-2000× for the whole grain and at 6000-9000× for sectioning the exine pattern. For each cultivars and rootstocks, 35 pollen grains were employed to determine the pollen size and the following morphological traits were measured: $(i)$ length of pollen along the polar axis $(P)$; $(i i)$ length of pollen along the equatorial diameter $(E)$; (iii) ratio of polar axis to equatorial diameter $(P / E)$; (iv) diameter of perforations $(D P)$; (v) number of perforations in $5 \mu \mathrm{m} \times 5 \mu \mathrm{m}(P N)$; (vi) width of muri $(W M)$; (vii) number of muri in $5 \mu \mathrm{m} \times 5 \mu \mathrm{m}(M N)$; (viii) distance between muri $(D M)$; $(\boldsymbol{i} \boldsymbol{x})$ width of grooves $(W G) ;(\boldsymbol{x})$ length of colpi $(C)$. The terminology follows that of Erdtman $[18,19]$ and Hesse et al. [20].

In order to find out the number of perforations and the number of muri on the exine surface, perforations and muri in $25 \mu^{2}$ were counted in 5-10 different locations on the surface. In order to calculate the diameter of the perforations,
Tab. 1 The species and cultivars investigated in this work.

\begin{tabular}{|c|c|c|}
\hline Species & Cultivar - rootstock & ID \\
\hline \multirow[t]{3}{*}{ P. armeniaca } & "Arancinu" & A1 \\
\hline & "Pirmintìu" & A2 \\
\hline & rootstock & A3 \\
\hline \multirow[t]{5}{*}{ P. domestica } & "Sittimmirinu" & $\mathrm{B} 1$ \\
\hline & "Rapparinu" & B2 \\
\hline & "Occhi di voi niuri" & B3 \\
\hline & "Occhi di voi biancu" & B4 \\
\hline & "Minacore" & B5 \\
\hline \multirow[t]{2}{*}{ P. avium } & "Cappuccia niura" & $\mathrm{C} 1$ \\
\hline & "Maiulina" & $\mathrm{C} 2$ \\
\hline \multirow[t]{3}{*}{ P. dulcis var. dulcis } & "Cavalera" & D1 \\
\hline & "Rappa" & $\mathrm{D} 2$ \\
\hline & rootstock & D3 \\
\hline P. dulcis var. amara & rootstock & $\mathrm{D} 4$ \\
\hline P. persica subsp. persica & "Pirmintìu" & E1 \\
\hline P. persica subsp. nucipersica & "Spaccarelli" & $\mathrm{E} 2$ \\
\hline
\end{tabular}

the width and the distance between muri and the width of grooves, for each of these parameters 25-35 different measures were conducted.

Statistical analyses of principal component analysis (PCA) component and matrix of similarity were realized using PAST software [21].

\section{Results}

\section{General pollen characteristics}

Pollen grains of all investigated species are symmetric, isopolar, monad, trizonocolpate (with three germinal furrows or colpi), medium-large sized. Regarding outline, in polar view, pollen grains are subtriangular and in equatorial view are elliptic (Fig. 1, Fig. 2, Tab. 2). The mean length of the polar axis varies from $38.54 \mu \mathrm{m}$ in B3 (P. domestica "Occhi di voi niuru") to $63.46 \mu \mathrm{m}$ in E1 (P. persica "Pirmintiu"). The mean of equatorial diameter varies from $20.39 \mu \mathrm{m}$ in B3 (P. domestica "Occhi di voi niuru") to $32.41 \mu \mathrm{m}$ in D1 (P. dulcis "Cavalera"). The shape of dried pollen grains is mainly prolate $(P / E=$ 1.33-2) except in A1 (P. armeniaca "Arancinu") and E1 $(P$. persica "Pirmintiu"), both with perprolate pollen grains $(P / E$ $>2$ ). The mean $P / E$ ratio ranges from 1.58 in $\mathrm{D} 1$ ( $P$. dulcis "Cavalera") to 2.02 in E1 ( $P$. persica "Pirmintì") and A1 ( $P$. armeniaca "Arancinu"). The smallest mean of pollen grains length was found in B3 and B4 ( $P$. domestica "Occhi di voi niuru" and "Occhi di voi biancu") and the largest mean pollen length occurs in E1 (P. persica "Pirmintiu").

Regarding exine sculpture, the ornamentations (muri) are described as striate type and they are separated by grooves, which appear longer in B1 ( $P$. domestica "Sittimmirinu") and shorter in A2 (P. armeniaca "Pirmintiù"). The surface of the pollen shows the largest perforations in B3 ( $P$. domestica "Occhi di voi niuru") and the smallest in D2 and D3 (P. dulcis "Rappa" and rootstock of $P$. dulcis var. dulcis) and the largest number of perforations is found in E1 (P. persica "Pirmintiu") and the smallest in rootstock of $P$. dulcis var. amara (Fig. 3, Fig. 4, Tab. 2). 

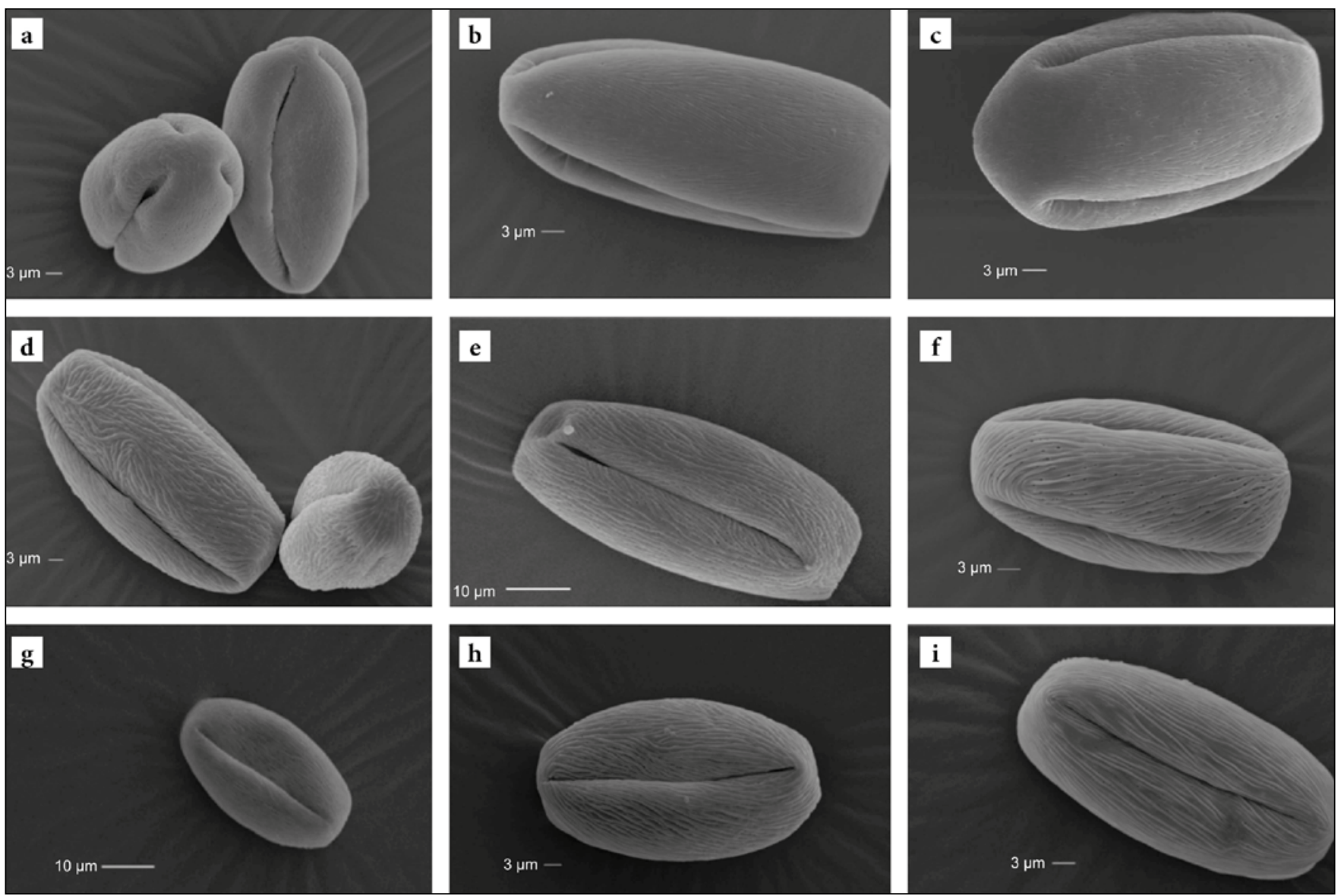

Fig. 1 Pollen shape of Prunus species and cultivars. a-c P. armeniaca: a "Arancinu"; b "Pirmintiu"; c Rootstock. d-h P. domestica: d "Sittimmirinu"; e "Rapparinu"; f "Occhi di voi niuri"; g "Occhi di voi biancu"; h "Minacore". i P. avium "Cappuccia niura".

\section{The species investigated: pollen morphological characterization}

\section{P. ARMENIACA TYPE}

Two cultivars and one rootstock of $P$. armeniaca (Tab. 1) were examined. All the pollen grains are large-sized (Fig. 1a-c), while the shape varies from prolate to perprolate (Fig. 1a-c). The mean of the polar diameter ranges between 52.92 and $54.30 \mu \mathrm{m}$ and the width varies from 26.64 to $28.27 \mu \mathrm{m}$. The $P / E$ ratio ranges between 1.92 and 2.02 . The mean length of colpi changes from 46.36 to $48.38 \mu \mathrm{m}$ (Tab. 2).

Concerning the exine sculpturing, the muri appear roughly parallel but too sloped compared to the polar axis and sometimes curved at the end near the colpi, \pm bifurcated and often intersecting (Fig. 3a-c). On the pollen surface small-sized perforations are distinguishable $(0.29-0.30 \mu \mathrm{m})$, which are dense in $\mathrm{A} 1\left(20.70 \pm 1.93\right.$ in $\left.25 \mu^{2}\right)$, and more reduced and sparsely distributed in A2 $(15.00 \pm 2.70)$ and in the rootstock (17.60 \pm 3.43 ). The width of muri ranges between 0.29 and $0.35 \mu \mathrm{m}$ (relatively narrow), while the arbitrary distance between them varies from 0.38 to $0.45 \mu \mathrm{m}$. The number of muri calculated in $25 \mu^{2}$ ranges between 16.20 and 21.00, while the width of grooves changes from 0.18 to $0.23 \mu \mathrm{m}$ (very narrow).

\section{P. DOMESTICA TYPE}

Five cultivars of this species were investigated (Tab. 1). The pollen grains show variable sizes (Fig. $1 \mathrm{~d}-\mathrm{h}$, Tab. 2) from medium (B3 and B4) to large (B1, B2, B5), while the shape is prolate. The mean length of polar axis ranges between 38.54 $\mu \mathrm{m}$ and $56.69 \mu \mathrm{m}$ and the length of equatorial diameter varies from $20.39 \mu \mathrm{m}$ to $29.52 \mu \mathrm{m}$. The length/width ratio changes from 1.88 to 1.97 . The length of germinal furrows varies from 31.13 to $48.58 \mu \mathrm{m}$ (Fig. 5). The arrangement of muri shown by the five cultivars is classifiable in the three following arbitrary ways (Fig. 3d-h):

(i) In B1 ("Sittimmirinu"), the muri are very well marked, branched, often intersecting and oriented in different directions (irregular pattern; Fig. 3d). The large muri (0.52 \pm 0.11 $\mu \mathrm{m})$ are separated by long intervals $(D M=0.64 \pm 0.18 \mu \mathrm{m})$ and by large grooves $(0.50 \pm 0.12 \mu \mathrm{m})$ with small-sized perforations $(0.30 \pm 0.08 \mu \mathrm{m})$. The number of perforations in $25 \mu \mathrm{m}^{2}$ is 17.80 \pm 3.12 , while the number of muri in $25 \mu \mathrm{m}^{2}$ is $11.60 \pm 1.71$.

(ii) In B2 ("Rapparinu"), the relatively large $(0.47 \pm 0.07 \mu \mathrm{m})$ muri appear roughly parallel but too sloped respect to polar axis, sometimes curved (the exine arrangement is similar to $P$. armeniaca, but more irregular), often intersecting and \pm bifurcated with very abundant $(P N=23.20 \pm 1.80)$ small-sized perforations situated in relatively short grooves $(W G=0.36$ $\pm 0.06 \mu \mathrm{m})$. The number of muri in $25 \mu \mathrm{m}^{2}$ is $14.00 \pm 0.88$ and the distance between them is $0.56 \pm 0.08 \mu \mathrm{m}$ (Fig. $3 \mathrm{e}$ ).

(iii) In B3 ("Occhi di voi niuru"), the muri are comparable to B2 but arrangement is more regular and separated by very narrow grooves $(0.28 \pm 0.06 \mu \mathrm{m})$ with relatively large perforations $(0.36 \pm 0.09 \mu \mathrm{m}$; Fig. $3 \mathrm{f})$. A similar arrangement of muri was observed in B4 ("Uocchi ri voi biancu") and B5 ("Minacore"; Fig. 3g,h) too, but the former presents relatively large perforations $(0.35 \pm 0.10 \mu \mathrm{m})$, and relatively narrow muri $(0.38 \pm 0.07 \mu \mathrm{m})$ separated by shorter grooves $(0.35 \pm 0.11 \mu \mathrm{m})$, the latter shows small perforations $(0.29 \pm 0.07 \mu \mathrm{m})$, large muri (like as B3 "Occhi di voi niuru") separated by large grooves $(W G=0.42 \pm 0.09 \mu \mathrm{m})$. The number of perforations in $25 \mu \mathrm{m}^{2}$ 

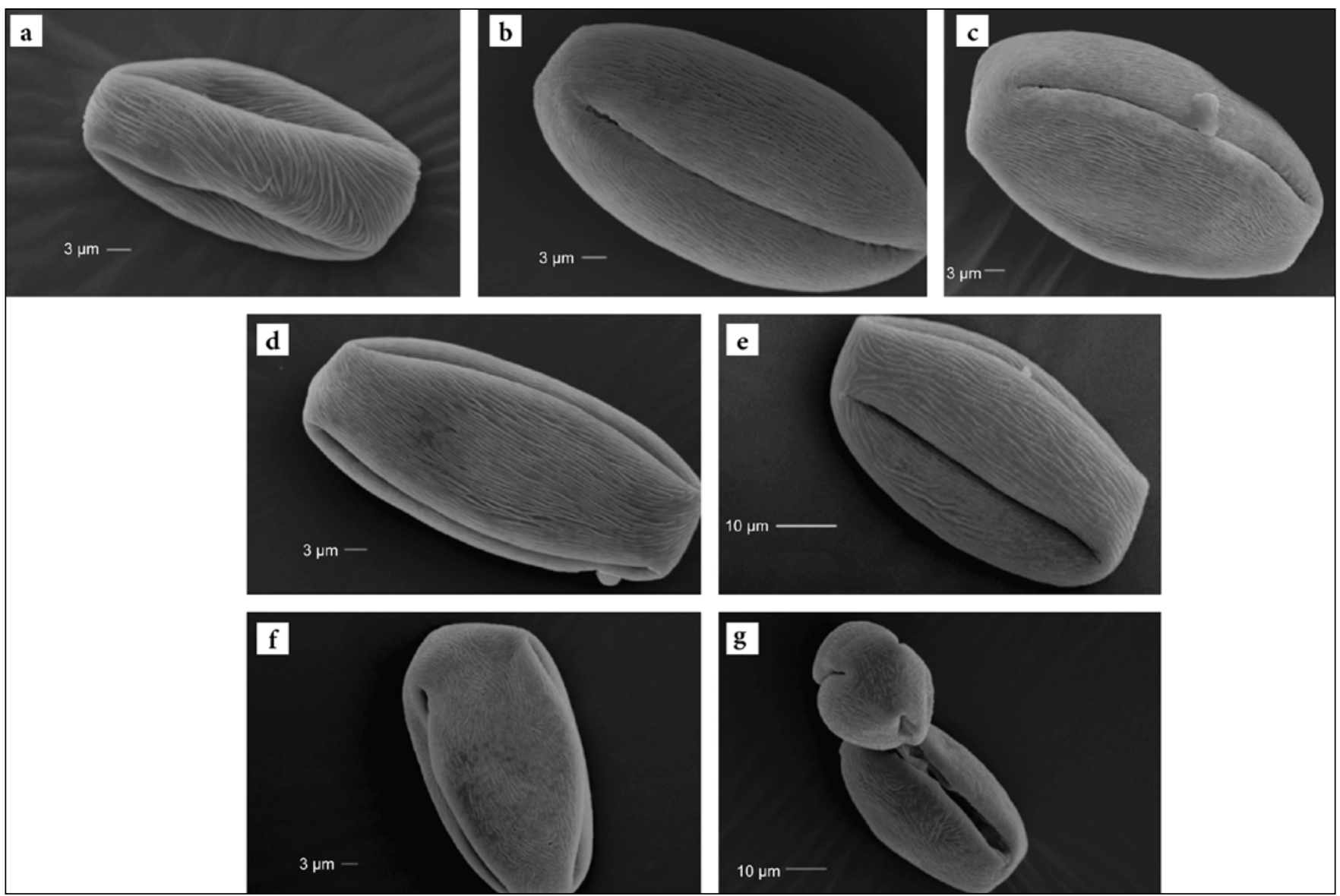

Fig. 2 Pollen shape of Prunus species and cultivars. a P. avium "Maiulina". b-d P. dulcis var. dulcis: b "Cavalera"; c "Rappa"; d rootstock. e P. dulcis var. amara rootstock. f $P$. persica subsp. persica "Pirmintìu”. g P. persica subsp. nucipersica "Spaccarelli".

is not variable in $\mathrm{B} 4$ and $\mathrm{B} 5(15.20,15.40)$, while the number of muri in $25 \mu^{2}$ is $13.60 \pm 1.00$ and $11.20 \pm 1.69$, respectively. The distance between the muri is longer in B5 ("Minacore") $(0.64 \pm 0.11 \mu \mathrm{m}$; Fig. 5).

\section{P. AVIUM TYPE}

Regarding this species, only two cultivars were examined (Tab. 1), both showing medium sized pollen grains and prolate shape (Fig. 1i, Fig. 2a, Tab. 2). The length of polar axis ranges between 45.74 and $48.20 \mu \mathrm{m}$, while the width of grain varies from 23.55 to $24.78 \mu \mathrm{m}$. The length/width ratio is similar (1.95 and 1.96). The length of colpi changes from 37.60 to $40.07 \mu \mathrm{m}$. The exine pattern (Fig. 3i, Fig. 4a) is not variable in arrangement compared to those observed in $P$. armeniaca and in $P$. domestica. The muri appear relatively narrow $(0.34,0.35 \mu \mathrm{m})$ like in apricot, separated by relatively short grooves $(0.36 \mu \mathrm{m})$. The perforations are very small $(0.26,0.28 \mu \mathrm{m})$ and sparsely distributed $\left(13.00,14.20\right.$ in $\left.25 \mu^{2}\right)$. The arbitrary distance between the muri is not very different $(0.55,0.56 \mu \mathrm{m})$, such as the muri number calculated in $25 \mu^{2}(12.80,13.20)$.

\section{P. DULCIS TYPE}

For this species two cultivars and two rootstocks were compared (Tab. 1). All the examined pollen grains are large sized and prolate shaped. The length of polar axis varies from 50.48 to $58.42 \mu \mathrm{m}$ (rootstock of $P$. dulcis), while the width of the grain ranges between 29.18 and $32.41 \mu \mathrm{m}$. The length/width ratio varies from 1.58 to 1.98 (Fig. 2b-e, Tab. 2).

The exine pattern is very regular (Fig. $4 \mathrm{~b}-\mathrm{e}$ ); in fact the muri are parallel to the colpi, very bifurcated, sometime fused. The diameter of perforations ranges between 0.24 and $0.32 \mu \mathrm{m}$ (from very small to medium-sized), while their mean number counted in $25 \mu \mathrm{m}^{2}$ varies from 11.00 to 17.40 (very few in D4 P. dulcis var. amara). The width of muri changes from 0.31 to $0.37 \mu \mathrm{m}$ (relatively narrow) and the arbitrary distance between muri ranges from 0.57 to $0.64 \mu \mathrm{m}$ (rather wide). The number of muri counted in $25 \mu \mathrm{m}^{2}$ results $10.40-15.20$, while the width of grooves varies from 0.34 to $0.40 \mu \mathrm{m}$. (medium in D2 and in the two rootstocks, large in D1).

\section{P. PERSICA TYPE}

Regarding this species the pollen from two cultivars belonging two different subspecies (Tab. 1) was observed. The examined samples show large-sized pollen grains but their shape varies from prolate to perprolate (Tab. 2). The length of polar axis (equatorial view) is 52.90 and $63.46 \mu \mathrm{m}$ and the width of equatorial diameter is 30.21 and $31.49 \mu \mathrm{m}$. The length/width ratio is 1.76 and 2.02. The length of colpi is 46.64 and 55.07. The diameter of perforations is not variable ( 0.30 and $0.31 \mu \mathrm{m}$, small-sized), while the number of perforations in $25 \mu^{2}$ is respectively 19.20 and 25.60 (the pits are very abundant in E1). The width of muri varies from 0.40 to $0.46 \mu \mathrm{m}$ and their arbitrary distance is 0.58 and $0.62 \mu \mathrm{m}$. The number of muri in $25 \mu \mathrm{m}^{2}$ is respectively 10.40 and 12.60 (few), while the width of grooves is 0.39 and $0.40 \mu \mathrm{m}$. Concerning exine arrangement we found some differences: in E1 ("Pirmintiu"), the exine pattern appears more irregular with bifurcated muri, often sinuous and sometime merged (Fig. 4f); in E2 ("Spaccarelli") the exine pattern is regular (Fig. 4g) with muri oriented like in $P$. dulcis. 
Tab. 2 Details of examined pollen characters of Prunus species and cultivars.

\begin{tabular}{clllllllllllllll} 
ID $\begin{array}{c}\text { Species/cultivar/ } \\
\text { rootstock }\end{array}$ & $P$ & $E$ & $P / E$ & $D P$ & $P N$ & $W M$ & $M N$ & $D M$ & $W G$ & $C$ \\
\hline
\end{tabular}

\section{P. armeniaca}

A1 "Arancinu”

A2 "Pirmintìu"

A3 rootstock

\section{P. domestica}

B1 "Sittimmirinu"

B2 “Rapparinu”

B3 "Uocchi ri voi

nivuri"

B4 "Uocchi ri voi biancu"

B5 "Minacore" $\begin{array}{lll}48.06-58.40 & 24.31-28.65 & 1.68-2.25\end{array}$ $53.73 \pm 2.34 \quad 26.64 \pm 0.86 \quad 2.02 \pm 0.12$ $\begin{array}{lll}46.30-57.28 & 26.15-31.87 & 1.70-2.05\end{array}$ $54.30 \pm 1.91 \quad 28.27 \pm 1.03 \quad 1.92 \pm 0.07$ $\begin{array}{lll}49.33-56.66 & 24.45-29.21 & 1.83-2.18\end{array}$ $52.92 \pm 1.38 \quad 26.77 \pm 1.08 \quad 1.98 \pm 0.09$ $\begin{array}{lllll}0.09-0.45 & 19.00-24.50 & 0.18-0.55 & 15.00-19.00 & 0.27-0.64\end{array}$ $\begin{array}{lllll}0.30 \pm 0.07 & 20.70 \pm 1.93 & 0.35 \pm 0.06 & 17.00 \pm 1.39 & 0.45 \pm 0.07\end{array}$ $\begin{array}{llllll}0.12-0.59 & 10.00-18.00 & 0.24-0.47 & 19.00-23.00 & 0.29-0.47\end{array}$ $\begin{array}{lllll}0.29 \pm 0.09 & 15.00 \pm 2.70 & 0.30 \pm 0.08 & 21.00 \pm 1.64 & 0.38 \pm 0.04\end{array}$ $\begin{array}{lllll}0.13-0.50 & 14.00-24.00 & 0.25-0.38 & 14.00-19.00 & 0.27-0.55\end{array}$ $\begin{array}{llllll}0.29 \pm 0.07 & 17.60 \pm 3.43 & 0.29 \pm 0.03 & 16.20 \pm 1.90 & 0.38 \pm 0.55\end{array}$
$0.18-0.36 \quad 44.52-50.32$ $0.23 \pm 0.04 \quad 48.19 \pm 2.28$ $0.12-0.24 \quad 42.62-49.57$ $0.18 \pm 0.03 \quad 46.36 \pm 2.21$ $0.13-0.38 \quad 46.25-50.00$ $0.23 \pm 0.05 \quad 48.38 \pm 1.43$

\section{P. avium}

C1 "Cappuccia niura"

$\begin{array}{lll}50.46-55.77 & 24.49-29.03 & 1.74-2.09\end{array}$ $52.96 \pm 0.96 \quad 26.91 \pm 0.89 \quad 1.97 \pm 0.07$ $\begin{array}{lll}47.81-55.86 & 24.63-33.42 & 1.63-2.09\end{array}$ $53.82 \pm 1.49 \quad 28.74 \pm 1.67 \quad 1.88 \pm 0.09$ $31.28-41.16 \quad 16.62-23.47 \quad 1.74-2.04$ $\begin{array}{lll}38.54 \pm 1.80 & 20.39 \pm 1.25 & 1.90 \pm 0.07\end{array}$ $33.05-42.89 \quad 17.96-24.52 \quad 1.35-2.19$ $39.62 \pm 1.95 \quad 21.22 \pm 1.38 \quad 1.96 \pm 0.15$ $\begin{array}{lll}53.28-62.79 & 26.74-32.69 & 1.68-2.20\end{array}$ $56.69 \pm 1.94 \quad 29.52 \pm 1.29 \quad 1.96 \pm 0.12$ $\begin{array}{lllll}0.12-0.59 & 14.00-23.00 & 0.35-0.88 & 9.00-14.00 & 0.35-1.18\end{array}$ $0.30 \pm 0.08 \quad 17.80 \pm 3.12 \quad 0.52 \pm 0.11 \quad 11.60 \pm 1.71 \quad 0.64 \pm 0.18$ $\begin{array}{lllll}0.18-0.55 & 20.00-25.00 & 0.36-0.73 & 13.00-15.00 & 0.36-0.73\end{array}$ $\begin{array}{lllll}0.30 \pm 0.08 & 23.20 \pm 1.80 & 0.47 \pm 0.07 & 14.00 \pm 0.88 & 0.56 \pm 0.08\end{array}$ $\begin{array}{llllll}0.18-0.55 & 20.00-29.00 & 0.36-0.73 & 11.00-16.00 & 0.36-0.82\end{array}$ $\begin{array}{lllll}0.36 \pm 0.09 & 24.60 \pm 3.20 & 0.46 \pm 0.07 & 13.20 \pm 1.90 & 0.59 \pm 0.09\end{array}$ $\begin{array}{lllll}0.18-0.64 & 13.00-20.00 & 0.18-0.55 & 12.00-15.00 & 0.36-0.82\end{array}$ $0.35 \pm 0.10 \quad 15.20 \pm 2.43 \quad 0.38 \pm 0.07 \quad 13.60 \pm 1.00 \quad 0.51 \pm 0.09$ $\begin{array}{llllll}0.18-0.55 & 13.00-18.00 & 0.36-0.55 & 9.00-14.00 & 0.36-1.00\end{array}$ $0.29 \pm 0.07 \quad 15.40 \pm 1.59 \quad 0.46 \pm 0.06 \quad 11.20 \pm 1.69 \quad 0.64 \pm 0.11$
$0.24-0.82 \quad 41.33-50.67$ $0.50 \pm 0.12 \quad 47.20 \pm 2.82$ $0.18-0.55 \quad 43.20-49.60$ $0.36 \pm 0.06 \quad 47.04 \pm 2.35$ $0.18-0.36 \quad 27.50-35.00$ $0.28 \pm 0.06 \quad 31.13 \pm 2.75$ $0.18-0.73 \quad 32.31-40.00$ $0.35 \pm 0.11 \quad 36.00 \pm 3.10$ $0.18-0.64 \quad 44.52-51.85$ $0.42 \pm 0.09 \quad 48.58 \pm 2.66$ $\begin{array}{lll}45.25-50.47 & 20.51-27.04 & 1.83-2.26\end{array}$ $48.20 \pm 1.02 \quad 24.78 \pm 1.15 \quad 1.95 \pm 0.07$ $\begin{array}{lll}42.48-48.04 & 18.71-26.03 & 1.81-2.33\end{array}$ $45.74 \pm 1.21 \quad 23.55 \pm 1.44 \quad 1.96 \pm 0.10$ $\begin{array}{lllll}0.12-0.47 & 10.00-17.00 & 0.24-0.47 & 11.00-16.00 & 0.35-0.71\end{array}$ $\begin{array}{lllll}0.28 \pm 0.07 & 13.00 \pm 2.70 & 0.35 \pm 0.04 & 13.20 \pm 1.69 & 0.55 \pm 0.06\end{array}$ $\begin{array}{llllll}0.12-0.47 & 10.00-20.00 & 0.24-0.41 & 11.00-14.00 & 0.35-0.76\end{array}$ $0.26 \pm 0.08 \quad 14.20 \pm 3.30 \quad 0.34 \pm 0.04 \quad 12.80 \pm 1.14 \quad 0.56 \pm 0.07$
$0.24-0.71 \quad 36.00-40.00$ $0.36 \pm 0.10 \quad 37.60 \pm 1.92$ $0.24-0.59 \quad 35.00-44.00$ $0.36 \pm 0.09 \quad 40.07 \pm 2.87$

\section{P. dulcis var. dulcis}

D1 "Cavalera"

D2 "Rappa"

D3 rootstock $\begin{array}{lll}46.19-56.61 & 27.19-38.51 & 1.32-2.02\end{array}$ $50.48 \pm 2.14 \quad 32.41 \pm 1.91 \quad 1.58 \pm 0.14$ $49.37-54.39 \quad 27.20-34.37 \quad 1.52-1.97$ $51.50 \pm 1.02 \quad 29.84 \pm 1.61 \quad 1.74 \pm 0.10$ $55.97-61.13 \quad 26.65-31.65 \quad 1.79-2.08$ $58.42 \pm 1.04 \quad 29.55 \pm 1.14 \quad 1.98 \pm 0.08$ $\begin{array}{lllll}0.09-0.45 & 7.00-16.00 & 0.18-0.55 & 12.00-14.00 & 0.36-0.91\end{array}$ $\begin{array}{lllll}0.28 \pm 0.07 & 13.00 \pm 3.10 & 0.37 \pm 0.07 & 12.40 \pm 0.78 & 0.60 \pm 0.10\end{array}$ $0.06-0.53 \quad 14.00-21.00 \quad 0.24-0.41 \quad 14.00-17.00 \quad 0.41-1.00$ $0.24 \pm 0.09 \quad 17.40 \pm 2.53 \quad 0.31 \pm 0.04 \quad 14.80 \pm 1.14 \quad 0.57 \pm 0.11$ $\begin{array}{lllll}0.13-0.38 & 14.00-20.00 & 0.25-0.38 & 13.00-16.00 & 0.38-0.88\end{array}$ $0.24 \pm 0.06 \quad 16.00 \pm 2.06 \quad 0.32 \pm 0.04 \quad 15.20 \pm 1.14 \quad 0.64 \pm 0.11$
$0.18-0.64 \quad 40.53-50.00$ $0.40 \pm 0.08 \quad 45.68 \pm 3.32$ $0.24-0.47 \quad 41.18-45.88$ $0.34 \pm 0.05 \quad 44.24 \pm 1.56$ $0.13-0.75 \quad 48.46-56.54$ $0.35 \pm 0.10 \quad 53.31 \pm 2.71$

P. dulcis var. amara

D4 rootstock

$\begin{array}{llllllllll}49.95-58.76 & 25.76-32.33 & 1.68-2.22 & 0.13-0.63 & 6.00-16.00 & 0.25-0.50 & 9.00-12.00 & 0.44-1.13 & 0.13-0.69 & 45.00-52.00\end{array}$

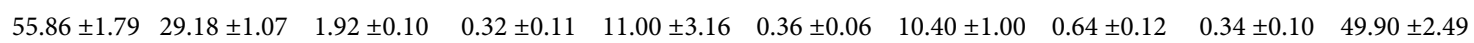

\section{P. persica subsp. persica}

E1 "Pirmintìu"

\section{P. persica subsp. nucipersica \\ E2 "Spaccarelli"}

$\begin{array}{lllllllll}58.50-67.98 & 29.34-33.22 & 1.88-2.14 & 0.09-0.73 & 20.00-28.00 & 0.36-0.55 & 11.00-14.00 & 0.36-0.73\end{array}$ $\begin{array}{llllllll}63.46 \pm 1.55 & 31.49 \pm 0.81 & 2.02 \pm 0.05 & 0.30 \pm 0.12 & 25.60 \pm 2.81 & 0.40 \pm 0.04 & 12.60 \pm 1.33 & 0.58 \pm 0.08\end{array}$
$0.18-0.73 \quad 51.98-58.53$ $0.40 \pm 0.10 \quad 55.07 \pm 2.07$

$C$ - length of colpi; $D M$ - distance between muri; $D P$ - diameter of perforations; $E$ - length of equatorial diameter; $M N$ - number of muri in 25 $\mu \mathrm{m}^{2} ; P$ - length of polar axis; $P / E$ - ratio of polar axis to equatorial diameter; $P N$ - number of perforations in $25 \mu \mathrm{m}^{2}$; $W G$ - width of grooves; $W M$ - width of muri. 

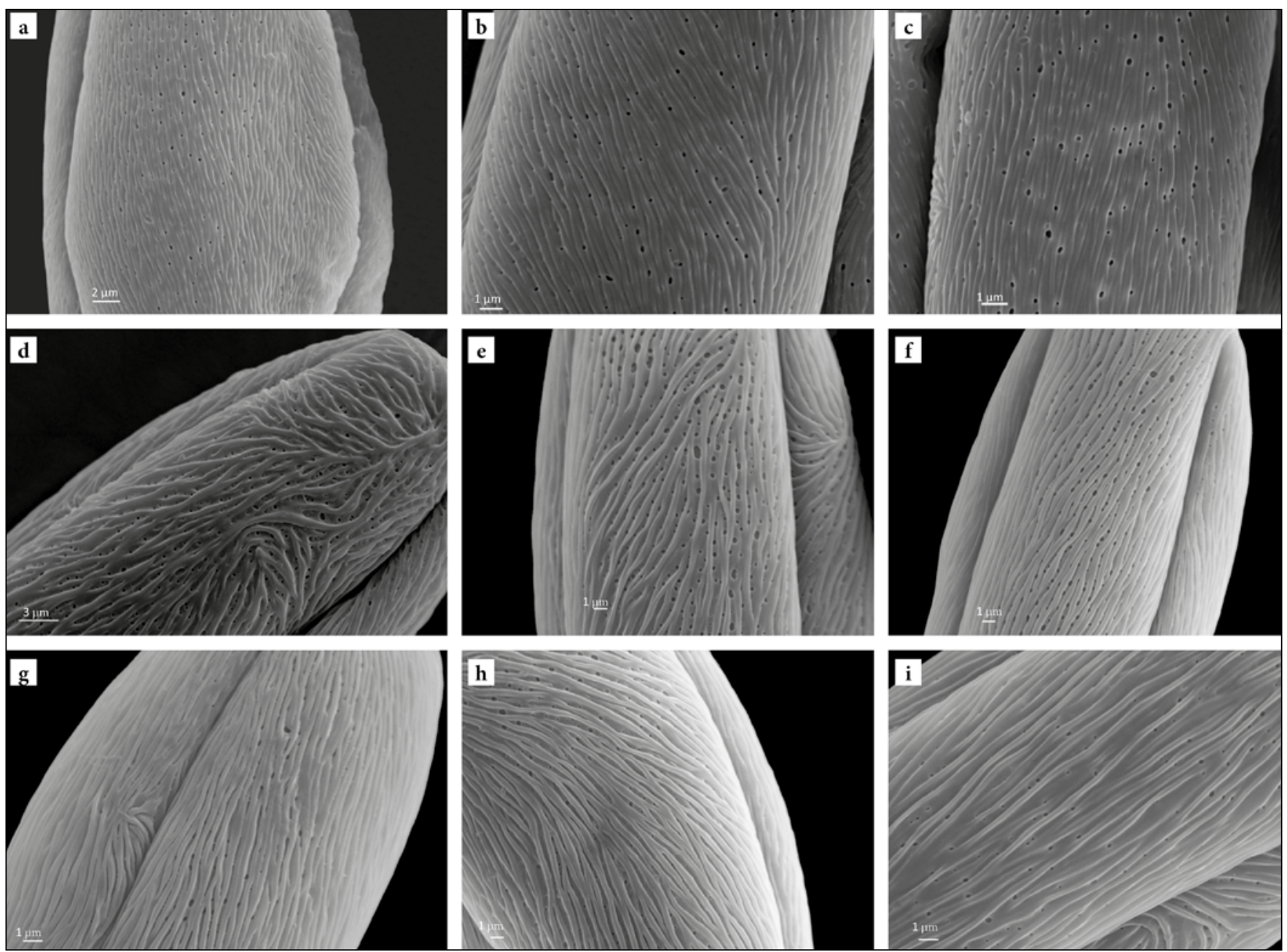

Fig. 3 Exine patterns of Prunus species and cultivars. a-c P. armeniaca: a "Arancinu"; b "Pirmintìu"; c rootstock. d-h P. domestica: d "Sittimmirinu"; e "Rapparinu"; f "Occhi di voi niuri"; g "Occhi di voi biancu"; h "Minacore". i P. avium "Cappuccia niura".

\section{Statistical and cluster analysis}

The resultant data of the morphological characteristics of pollen grains were statistically analysed.

Statistical analysis was conducted using PCA. Analysing the correlation matrix, three principal components were needed to account for the $80.46 \%$ of the total variation, whose $64.32 \%$ was represented by the first two components (Tab. 3) consisting in length of polar axis and length of equatorial diameter.

The principal component $(P C)$ score, associated to each variable (Tab. 4) on the three principal components, identifies the variables that mostly define them. The $P C 1$ defined the $33.58 \%$ of cumulative variance and this is positively correlated with following variables: length of polar axis $(P)$, width of equatorial diameter $(E)$, width of muri $(W M)$, width of grooves $(W G)$, distance between muri and length of colpi. The PC2 signified $30.74 \%$ of cumulative variance and this is positively correlated with: $P, E, P / E$ ratio, $M N$ (number of muri in $25 \mu \mathrm{m}^{2}$ ) and $C$. The $P C 3$ defined $16.14 \%$ of cumulative variance and it is positively correlated with all variables except $E, D M$ and $W M$. The projections of the $P C$ loadings defined by the first two principal components allow us to visualize the position of Prunus cultivars and rootstocks as shown in score plot (Fig. 6).

In addition, the differences among the samples analysed on the basis of parameters measured on their pollen grains, were verified by the cluster analysis using UPGMA algorithm on the basis Euclidean distance matrix. The analysis of the UPGMA tree (Fig. 7; constructed on the strenght of quantitative traits of pollen grains) revealed three principal groups of morphological similarity: (i) B5 (P. domestica "Minacore"), rootstocks of $P$. dulcis (D3 and D4); D1 (P. dulcis var. dulcis "Cavalera"), rootstock of P. armeniaca (A3); A1 (P. armeniaca "Arancinu"); B2 (P. domestica "Rapparinu"); B1 (P. domestica "Sittimmirinu"); E2 (P. persica subsp. nucipersica "Spaccarelli"); D2 (P. dulcis var. dulcis "Rappa") and A2 (P. armeniaca "Pirmintiu"); (ii) $\mathrm{C} 1$ and $\mathrm{C} 2$ (P. avium "Cappuccia nìura" and "Maiulina"); (iii) B3 and B4 (P. domestica "Occhi di voi niuri" and "Occhi di voi biancu"). E1 (P. persica subsp. persica "Pirmintiu") resulted in a distinct clade.

\section{Discussion}

The genus of Prunus s.l. comprises more domesticated and cultivated species of temperate fruits than the other genera in the family of Rosaceae. One of the obvious reasons for the abundant domestication might be the coincidence between the location of the centre of variability of Prunus and/or of the places of the first high civilization of human history [22]. Many species such as plum, peach, apricot, almond, have attracted the human interest for their edible fruits, while others are planted also for their timber and their ornamental value like $P$. avium (cherry).

In this paper, the detailed analysis of morphological characters of the pollen grains showed that in all the examined 

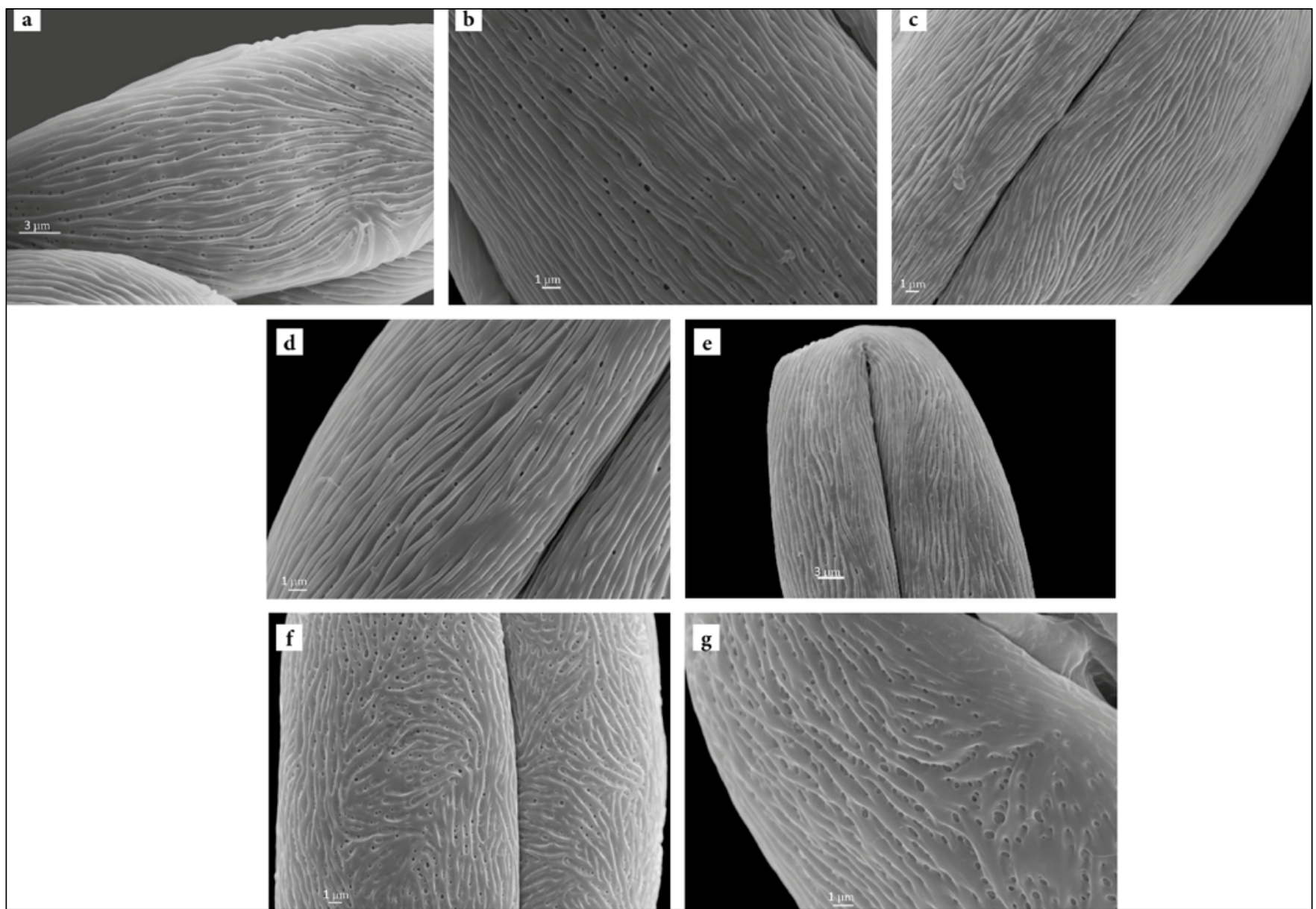

Fig. 4 Exine patterns of Prunus species and cultivars. a P. avium "Maiulina". b-d P. dulcis var. dulcis: b "Cavalera"; c "Rappa"; d rootstock. e $P$. dulcis var. amara rootstock. f $P$. persica subsp. persica "Pirmintìu”. $\mathbf{g}$ P. persica subsp. nucipersica "Spaccarelli".

Tab. 3 Percentage variance contributions by principal components for the dimension and characteristics of Prunus pollen grains.

\begin{tabular}{cccc}
\hline \multicolumn{4}{c}{ Total variance explained } \\
\hline PCs & Eigenvalue & Variance (\%) & Cumulative variance (\%) \\
\hline & & & \\
1 & 3.36 & 33.58 & 33.58 \\
2 & 3.07 & 30.74 & 64.32 \\
3 & 1.61 & 16.14 & 80.46 \\
4 & 0.92 & 9.20 & 89.66 \\
5 & 0.52 & 5.22 & 94.88 \\
6 & 0.25 & 2.52 & 97.40 \\
7 & 0.15 & 1.53 & 98.93 \\
8 & 0.07 & 0.67 & 99.60 \\
9 & 0.04 & 0.39 & 99.98 \\
10 & 0.00 & 0.02 & 100 \\
\hline
\end{tabular}

PCs - principal components.

samples they are symmetric, isopolar, monad, trizonocolpate (with three germinal furrows or colpi), medium-large sized. Regarding outline, in polar view, pollen grains are subtriangular and in equatorial view are elliptic. In the general evaluation of pollen surface, all the pollen grains show striate type of exine sculpture with perforations in the grooves
Tab. 4 Principal component analysis loadings and contributions of the principal components.

\begin{tabular}{cccc}
\hline \multicolumn{5}{c}{ PCA loadings } \\
\hline Variables & $\boldsymbol{P C} \mathbf{1}$ & $\boldsymbol{P C} \mathbf{2}$ & $\boldsymbol{P C} \mathbf{3}$ \\
\hline & & & \\
$E$ & 0.31 & 0.42 & 0.28 \\
$P$ & 0.37 & 0.37 & -0.03 \\
$P / E$ & -0.15 & 0.03 & 0.50 \\
$D P$ & -0.14 & -0.39 & 0.31 \\
$P N$ & 0.00 & -0.09 & 0.62 \\
$W M$ & 0.28 & -0.38 & 0.31 \\
$M N$ & -0.39 & 0.33 & 0.09 \\
$D M$ & 0.45 & -0.23 & -0.11 \\
$W G$ & 0.46 & -0.22 & -0.07 \\
$C$ & 0.30 & 0.42 & 0.25 \\
\hline
\end{tabular}

PC1-3 - principal components.

confirming the general characteristics for the pollen of Rosaceae [23-27].

In fact an useful feature for distinguishing the species in the Rosaceae family consists in examining exine sculptures, the most variable morphological character of the pollen surface. Different exine sculptures were observed in some genera of 

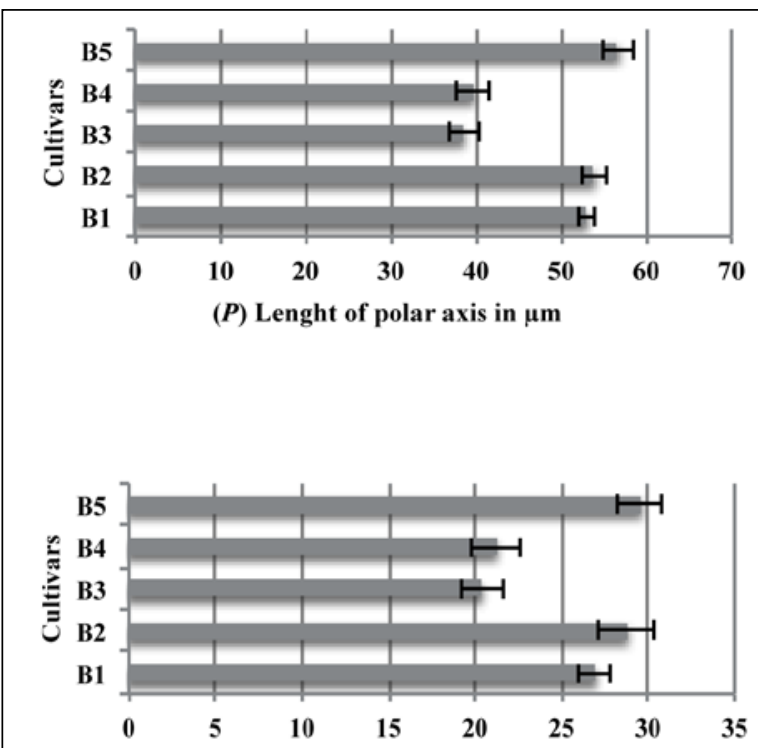

(E) Lenght of equatorial diameter in $\mu \mathrm{m}$
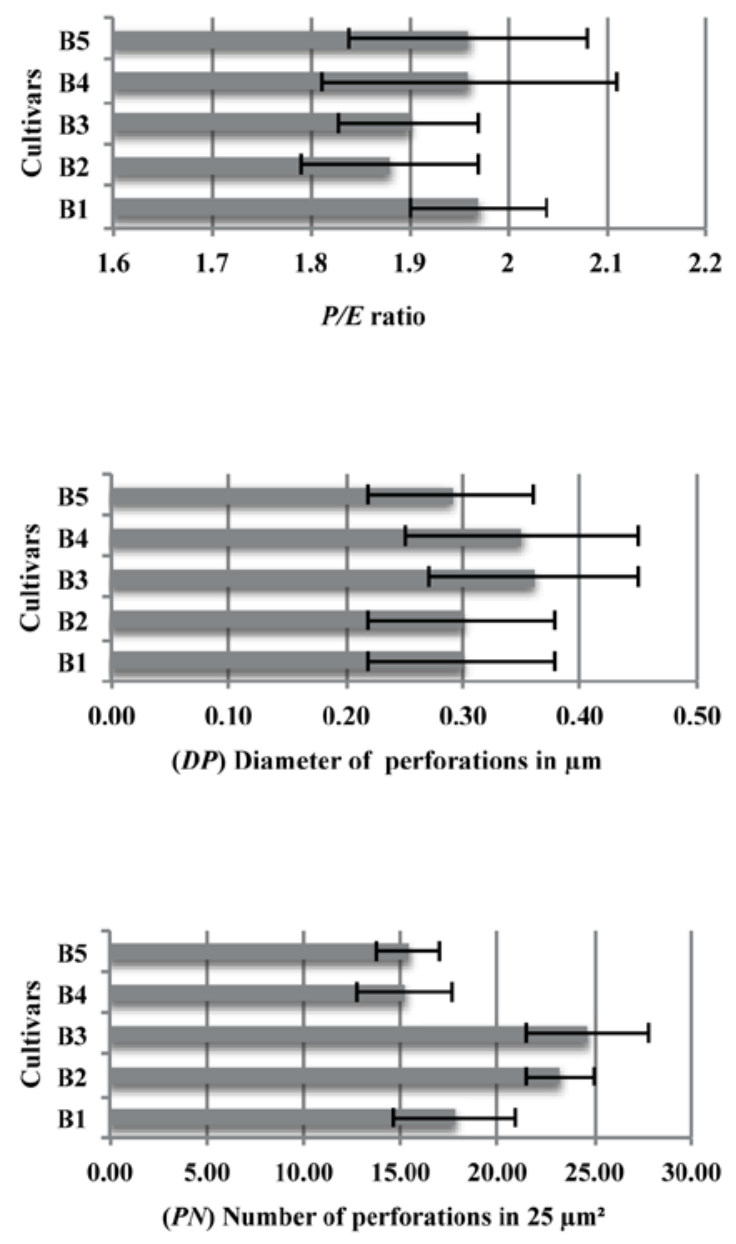
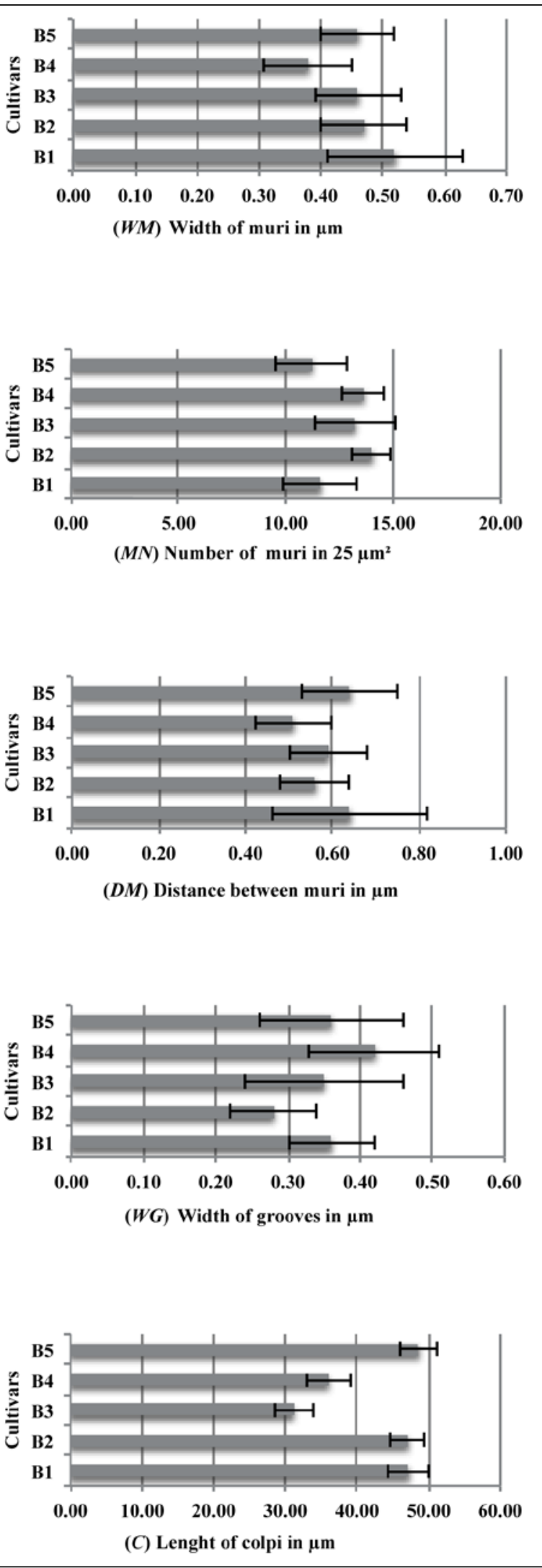

Fig. 5 Graphics of pollen morphology features in P. domestica.

Rosaceae family including Turkish Crataegus [28] and some members of rosaceous and Prunoideae in Canada [24-26]. Our results showed similar arrangement of the muri organisation in $P$. armeniaca, $P$. avium and some cultivars of $P$. domestica in which they were roughly parallel but too sloped compared to the polar axis and sometimes curve; in P. dulcis and in P. persica subsp. nucipersica the muri are regular and perfectly parallel.
The muri pattern observed in surface of B1 (P. domestica "Sittimmirinu") pollen grain, was markedly branched, while in P. persica subsp. persica "Pirmintìu" (E1) it was very irregular and sinuous. Irregular pattern of exine ornamentation was observed in one Italian cultivar ("Maria Emilia") of $P$. persica cultivated in Argentina [29], that presented a globular structure. Regarding to the dimensional parameters, $P$. persica was 


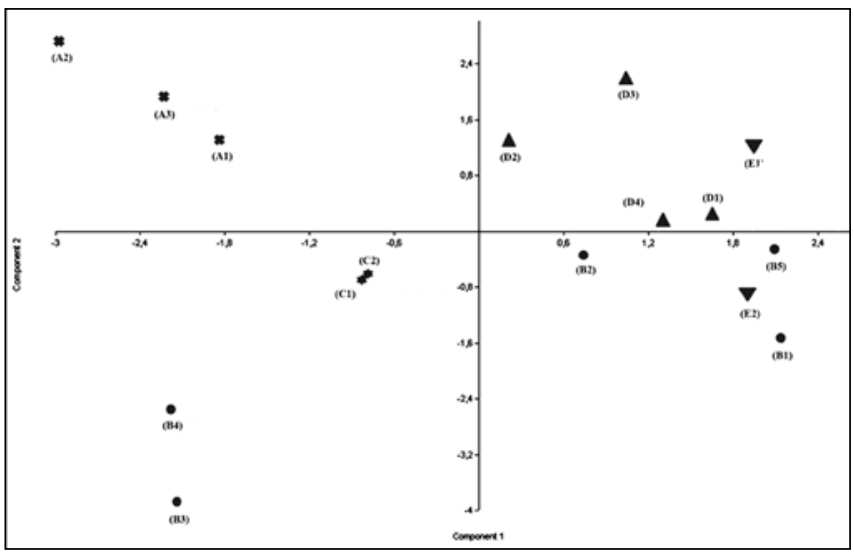

Fig. 6 Scatter diagram of Prunus species and cultivars in the first and second principal components.

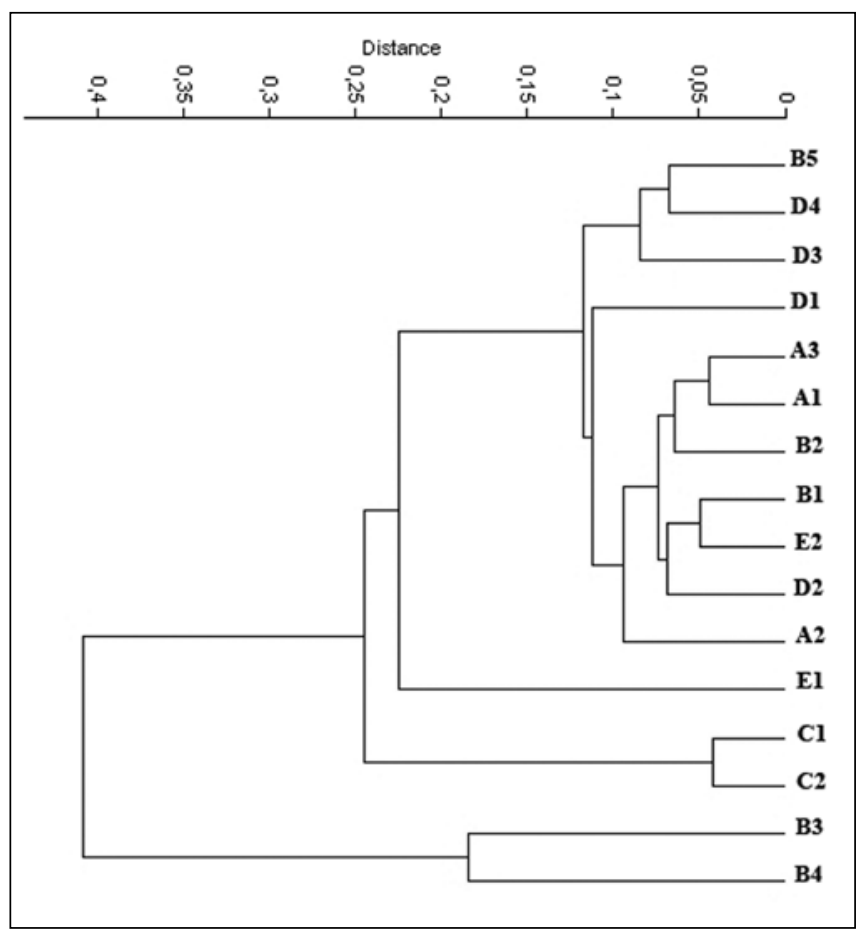

Fig. 7 UPGMA tree of Prunus species and cultivars constructed on the basis of the Euclidean distance matrix. Follow Tab. 1 for species and cultivar shortcuts explanations.

ranked first in terms of pollen length and width (mean value $58.18 \times 38.85 \mu \mathrm{m}$ among two cultivars examined), followed by $P$. dulcis (mean value $54.07 \times 30.25 \mu \mathrm{m}$ ). Our data agreed with those reported by Evrenosoğlu \& Misirli [4] for pollen size and for $P / E$ ratio mean value in peach and almond and for the diameter of perforations in almond; concerning the width of muri in peach, moreover, they obtained similar values to those shown by Gilani et al. [30]. The average pollen length and width, as well as $P / E$ and the width of muri mean value in P. armeniaca, obtained in our study, are similar to the data observed by Arzani et al. [31], while Gilani et al. [30] reported similar range value as to $D M$ (distance between muri) and $W M$. Otherwise, from the observations on almond from Iran reported by Vadafar et al. [32], pollen grains of $P$. dulcis s.l. (D1-D4) presented small and medium sized perforations; their number decreases in P. dulcis var. amara (D4).
The measurements made on $P$. domestica pollen grains showed a clear variability in the most morphological investigated characteristics. However, our dimensional range data $(P$ $\times E, D P, D M, W M)$ can be only partially compared to those described by Evrenosoğlu and Misirli [4] and Gilani et al. [30]. In the current study, pollen size in P. avium is larger than the samples analysed by Gilani et al. [30], while the range of mean values of $D M$ and $W M$ was comparable. In order to analyse the variance, the correlation matrix shows the variables that mostly identify and define the three principal components: $P C 1$ is strongly correlated with $W G(0.46)$ variable, $P C 2$ with $C(0.42)$ variable and $P C 3$ with $P N(0.62)$.

The cluster analysis shows a great morphological affinity among nine cultivars and three rootstocks, while the two cultivars of $P$. avium (C1 and $\mathrm{C} 2$ ) were different due to the medium-sized pollen grains (45.74-48.20 $\mu \mathrm{m} \times 23.55-24.78$ $\mu \mathrm{m})$ and the very small diameter of perforations $(0.26-0.28$ $\mu \mathrm{m}$, respectively), which were sparsely distributed. Similar to cherry, plum cultivars B3 and B4 ("Occhi di voi niuri" and "Occhi di voi biancu") were characterized by medium-sized pollen but smaller than cherry $(38.54-39.62 \mu \mathrm{m} \times 20.39-21.22$ $\mu \mathrm{m})$ and the large diameter of perforations. Perforations on the exine surface of the P. persica "Pirmintì" pollen were very abundant $\left(25.60\right.$ in $\left.25 \mu \mathrm{m}^{2}\right)$ and small-sized, while the size of pollen grains was the largest (63.46-31.49 $\mu \mathrm{m})$.

In conclusion, the fine observations on pollen surface allowed us to characterize further the different cultivars and in particular to point out the great variability found in the fruits and also in other morphological traits [1]. In fact, particularly, examining $P$. domestica cultivars we discovered a correlation of variability between the pollen grains structures and the fruits shapes. This latter species, shows the highest diversity of the observed parameters, probably because of its hybrid origin according to the hypothesis of Zeven \& De Wet [33]. Moreover, in the subfamily of Prunoideae the exine structure could be considered an auxiliary diagnostic character, as also reported for the genus Rosa [17], to increase the number of the taxonomical characters that can be utilized for discrimination of the species.

Other studies are in progress to analyse and to preserve this important tree-patrimony realized by the human activities in several centuries.

\section{Acknowledgements}

We are very grateful to Dr. Carmela Di Liberto of the same University Department for providing SEM photos.

\section{References}

1. Schicchi R, Marino P, Raimondo FM. Individuazione, valutazione e raccolta del germoplasma delle specie arboree da frutto di prevalente interesse negli agrosistemi tradizionali della Sicilia. Palermo: Dipartimento Azienda Regionale Foreste Demaniali; 2008.

2. Lee S, Wen J. A phylogenetic analysis of Prunus and the Amygdaloideae (Rosaceae) using ITS sequences of nuclear ribosomal DNA. Am J Bot. 2001;88(1):150-160. http:// dx.doi.org/10.2307/2657135

3. Dönmez AA, Yildirimli S. Taxonomy of genus Prunus L. (Rosaceae) in Turkey. Turk J Bot. 2000;24:187-202. 
4. Evrenosoğlu Y, Misirli A. Investigations on the pollen morphology of some fruit species. Turk J Agric For. 2009;33:181-190.

5. Fogle HW. Identification of clones within four tree fruit species by pollen exine patterns. J Amer Soc Hort Sci. 1977;102:552-560.

6. Fogle HW. Identification of tree fruit species by pollen ultrastructure. J Amer Soc Hort Sci. 1977;102:548-551.

7. Maas JL. Pollen ultrastructure of strawberry and other small fruitcrops. J Amer Soc Hort Sci. 1977;77:548-555.

8. Cargnello G, Carraro L, Lombardo G, Gerola FM. Pollen morphology of Picolit grown in different Italian regions. Vitis. 1980;19:2016.

9. Galletta GJ. Pollen and seed management. In: Moore JN, Janick J, editors. Methods in fruit breeding. West Lafayette IN: Purdue University Press; 1983. p. 23-47.

10. Hebda RJ, Chinnappa CC, Smith BM. Pollen morphology of the Rosaceae of Western Canada. Grana. 1988;27(2):95113. http://dx.doi.org/10.1080/00173138809432836

11. Merev N. Doğu Karadeniz Bölgesi’nde doğal olarak yetişen kuşburnu (Rosa L.) taksonlarının palinolojik yönden incelenmesi. Kuşburnu Sempozyumu Bildiriler Kitabı, Gümüşhanev. Ahi Evran Üniversitesi, Ziraat Fakültesi, Bahçe Bitkileri Bölümü: Kirşehir; 1996. p. 47-54.

12. Jones GD. Pollen as indicators of source areas and foraging resources [Internet]. 2001 [cited 2011 Jun 1]; Available from: http://pollen.usda.gov

13. Perveen A, Qaiser M. Pollen flora of Pakistan - XVII. Illecebraceae. Pak J Bot. 2003;35:141-144.

14. Chung KS, Elisens W, Skvarla J. Pollen morphology and its phylogenetic significance in tribe Sanguisorbeae (Rosaceae). Plant Syst Evol. 2010;285(3):139-148. http://dx.doi. org/10.1007/s00606-009-0262-9

15. Moore P, Webb JA, Collinson ME. Pollen analysis. 2nd ed. Oxford: Blackwell Scientific Publications; 1991.

16. Bednorz L, Maciejewska-Rutkowska I, Wronska-Pilarek D, Fujiki T. Pollen morphology of the polish species of the genus Sorbus L. Acta Soc Bot Pol. 2005;74(4):315-322.

17. Wrońska-Pilarek D, Jagodziński A. Systematic importance of pollen morphological features of selected species from the genus Rosa (Rosaceae). Plant Syst Evol. 2011;295(1):5572. http://dx.doi.org/10.1007/s00606-011-0462-y

18. Erdtman G. An introduction to pollen analysis. Stockholm: Waltham Mass; 1943.

19. Erdtman G. On terminology in pollen and spore morphology. Grana. 1958;1(3):6-9. http://dx.doi. org/10.1080/00173135809436053
20. Hesse M, Halbritter H, Zetter R, Weber M, Buchner R, Frosch-Radivo A, et al. Pollen terminology: an illustrated handbook. Vienna: Springer; 2009.

21. Hammer $\varnothing$, Harper DAT, Ryan PD. PAST: paleontological statistics software package for education and data analysis. Palaeontol Electron. 2001;4(1):1-9.

22. OECD. Stone fruits (Prunus spp.). OECD Agriculture \& Food. 2008;2006(21):628-660.

23. Ueda Y, Tomita H. Morphometric analysis of pollen exine patterns in roses. J Japan Soc Hort Sci. 1989;58(1):211-220.

24. Hebda RJ, Chinnappa CC. Studies on pollen morphology of Rosaceae in Canada. Rev Palaeobot Palynol. 1990;64(1-4):103-108. http://dx.doi. org/10.1016/0034-6667(90)90123-Z

25. Hebda RJ, Chinnappa CC. Pollen morphology of the Rosaceae of western Canada. III. Geum. Can J Bot. 1990;68(6):1369-1378. http://dx.doi.org/10.1139/b90-175

26. Hebda RJ, Chinnappa CC, Smith BM. Pollen morphology of the Rosaceae of western Canada. IV. Luetkea, Oemleria, Physocarpus, Prunus. Can J Bot. 1991;69(12):2583-2596. http://dx.doi.org/10.1139/b91-322

27. Zhou LH, Wei ZX, Wu ZY. Pollen morphology of Prunoideae of China (Rosaceae). Acta Bot Yunnan. 1999;21:207-211.

28. Dönmez E. Pollen morphology in Turkish Crataegus (Rosaceae). Bot Helv. 2008;118(1):59-70. http://dx.doi. org/10.1007/s00035-008-0823-5

29. Radice S, Ontivero M, Giordani E, Bellini E. Morphology and physiology of pollen grains of Italian Prunus persica (L.) Batsch cultivars grown in Argentina. Adv Hort Sci. 2003;17(2):93-96.

30. Gilani SA, Qureshi RA, Khan AM, Potter D. Morphological characterization of the pollens of the selected species of genus Prunus Linn. from Northern Pakistan. Afr J Biotechnol. 2010;9(20):2872-2879.

31. Arzani K, Nejatian MA, Karimzadeh G. Apricot (Prunus armeniaca) pollen morphological characterisation through scanning electron microscopy, using multivariate analysis. N Z J Crop Hort Sci. 2005;33(4):381-388. http://dx.doi.org /10.1080/01140671.2005.9514374

32. Vafadar M, Attar F, Maroofi H, Mirtadzadini M. Pollen morphology of Amygdalus L. (Rosaceae) in Iran. Acta Soc Bot Pol. 2010;79(1):63-71.

33. Zeven AC, de Wet J. Dictionary of cultivated plants and their regions of diversity: excluding most ornamentals, forest trees and lower plants. Dehra Dun: International Book Distributors; 1993. 